\title{
Mudanças no novo Código de Nomenclatura para Algas, Fungos e Plantas (Código de Melbourne)
}

Jefferson Prado ${ }^{1,3}$, Regina Yoshie Hirai ${ }^{1}$ e Ana Maria Giulietti ${ }^{2}$

Recebido em 29/08/2011. Aceito em 6/09/2011

\section{RESUMO}

(Mudanças no Código de Nomenclatura para Algas, Fungos e Plantas (Código de Melbourne)). São apresentadas as principais alterações aprovadas para o Código de Melbourne, destacando-se a publicação válida de novidades nomenclaturais através de meio eletrônico e a possibilidade de descrições de novos táxons em inglês (além de latim). Aspectos sobre os mecanismos para votação de novas propostas para modificar o Código também são discutidos.

Palavras-chave: Austrália, novidades, publicação eletrônica, regras de nomenclatura

\begin{abstract}
(Changes to the Code of Nomenclature for Algae, Fungi, and Plants (Melbourne Code)). The most important changes to the Melbourne Code are presented, with attention to the valid publication of nomenclatural novelties in electronic media and the possibility to describe new taxa in English (besides Latin). Other aspects about the procedures to vote on proposals to modify the Code are also discussed.
\end{abstract}

Key words: Australia, electronic publication, nomenclature rules, novelties

A Sessão de Nomenclatura é o principal foro de discussão e votação das propostas de alteração do Código Internacional de Nomenclatura Botânica (CINB). Ela acontece em intervalos de seis anos, na semana que antecede o Congresso Internacional de Botânica. As propostas são publicadas na revista Taxon, que pertence à International Association for Plant Taxonomy (IAPT) e é o veículo oficial de divulgação de Nomenclatura Botânica. Para a reunião deste ano, em Melbourne (Austrália), entre 18 e 22 de julho, foram publicadas 338 propostas (McNeill \& Turland 2011); outras 15 propostas foram incluídas durante a Sessão.

As propostas para o Código passam por um processo de votação preliminar "pelo correio". Nesta etapa, tem direito a voto os autores das propostas, os sócios da IAPT e os membros dos Comitês Permanentes de Nomenclatura (Comitê Geral de Nomenclatura e Comitês Específicos para cada grupo taxonômico). Propostas com mais de 75\% de votos positivos ou negativos são aprovadas ou rejeitadas, respectivamente; as demais são incluídas na pauta da Sessão de Nomenclatura para votação presencial. Nesta segunda etapa, tem direito a voto todos os presentes na Sessão de Nomenclatura. Os votos podem ser individuais ou institucionais. Cada Herbário credenciado no Index Herbariorum pode ser representado por um delegado e seu voto pode valer de um a sete, conforme o tamanho do acervo e o número de doutores associados à instituição. Neste ano, o Herbário do Jardim Botânico do Rio de Janeiro (RB, cinco votos), Herbário do Instituto de Botânica (SP, quatro votos) e Herbário da Universidade de São Paulo (SPF, dois votos) foram representados na Sessão de Nomenclatura por Jefferson Prado, que acumulou 11 votos institucionais, além de seu voto individual. Para ser incluída no Código,

\footnotetext{
${ }^{1}$ Instituto de Botânica, Herbário SP, São Paulo, SP, Brasil

${ }^{2}$ Universidade Estadual de Feira de Santana, Departamento de Ciências Biológicas, Herbário HUEFS, Feira de Santana, BA, Brasil

${ }^{3}$ Autor para correspondência: jefferson.prado@pq.cnpq.br
} 
uma proposta deve ter pelo menos $60 \%$ de votos favoráveis durante as votações presenciais. Outras deliberações gerais também podem ser acatadas, desde que recebam pelo menos $50 \%+1$ de votos positivos.

Em Melbourne, a Sessão de Nomenclatura foi coordenada por Sandra Knapp (The Natural History Museum, Londres, BM), John McNeill (Royal Botanic Gardens, Edimburgo, E) e Nicholas Turland (Missouri Botanical Garden, St. Louis, MO). Participaram das atividades aproximadamente 290 pessoas, a maioria da Austrália, Estados Unidos e Europa, sendo apenas quatro representantes da América do Sul, um da Argentina (Dra. Renée Fortunato, INTA, Buenos Aires) e três brasileiros (os autores desta nota). O Comitê de Nomeação, que tem a função de nomear os membros do Comitê Editorial do Código de Melbourne e dos Comitês Permanentes de Nomenclatura (Comitê Geral de Nomenclatura e Comitês para cada grupo taxonômico: algas, fungos, briófitas, fósseis e plantas vasculares) foi estabelecido no início da sessão; um de nós (JP) participou como membro deste Comitê de Nomeação.

\section{As principais decisões foram:}

1. O título do novo Código será International Code of Nomenclature for algae, fungi, and plants (Melbourne Code), refletindo os avanços nas classificações dos organismos abrangidos pelo Código.

2. Os termos "isolectótipo", "isoneótipo" e "isoepítipo" serão incluídos como recomendação no Artigo 9.

3. Os apêndices II-VI serão publicados apenas na forma online.

4. Sinais tipográficos, números ou letras estranhas ao alfabeto latino (e.g., letras gregas $\alpha, \beta$, $\gamma$, etc., para designar variedades) não constituem publicações válidas de níveis hierárquicos e não são consideradas parte do nome. Esta informação será incluída como nota no Artigo 32.

5. Publicações eletrônicas: novos artigos serão introduzidos no Código para regulamentar a publicação eletrônica de novidades nomenclaturais. As propostas relacionadas a este assunto foram publicadas pelo Comitê Especial para Publicações Eletrônicas (Special Committee on Electronic Publication 2010) estabelecido na Sessão de Nomenclatura de Viena, em 2005. Os aspectos relacionados a esta novidade que merecem maior destaque são:

A - Nova redação do Artigo 29.1, que incluíra a frase (modificações em itálico) "Publicação é efetiva, ... A publicação também é efetiva pela distribuição eletrônica da matéria em Formato de Documento Portátil (PDF; veja também Art. 29.3 e Rec. 29A.1) em uma publicação online com um Número Padrão Internacional de Séries (ISSN) ou com um Número Padrão Internacional de Livros (ISBN). Não é efetiva por ... qualquer meio eletrônico, exceto como descrito acima".

B - Será aceito apenas o formato PDF (ou formatos subsequentes) para a publicação eletrônica de novidades nomenclaturais; qualquer outro formato de arquivo eletrônico não constituirá publicação efetiva e consequentemente válida.
C - A aceitação de um formato diferente do PDF deverá antes ser aprovada pelo Comitê Geral de Nomenclatura.

D - Publicações de versões eletrônicas e impressas na mesma data devem conter conteúdo e paginação idênticos. Caso elas apresentem diferenças de conteúdo ou paginação, a versão eletrônica terá prioridade.

6. O Capítulo II será reformulado para uniformização das explanações sobre condições de publicação válida de nomes, no que diz respeito a citações diretas e indiretas de basiônimos. O Comitê Editorial do Código de Melbourne ficou encarregado de preparar essa reformulação.

7. Os termos status novum e nomen novum (Art. 6) serão alterados e terão uma tradução em inglês compatível com seus significados no Código. $\mathrm{O}$ uso deles será explicitado e uniformizado. A redação dessas alterações será discutida pelo Comitê Editorial.

8. A publicação válida de nomes de novos táxons deverá ser acompanhada de uma descrição ou diagnose em latim ou inglês (Art. 36). As decisões acatadas durante a Sessão de Nomenclatura passam a valer a partir do último dia do Congresso Internacional de Botânica, quando as mesmas são ratificadas pela Assembléia de Encerramento. No entanto, ficou acordado que essa modificação entraria em vigor somente em $\mathbf{1}^{\circ}$ de janeiro de 2012, em vez de $1^{\circ}$ agosto de 2011. Ela vale para as descrições ou diagnoses de todos os organismos tratados no Código.

9. Nomes novos de fungos deverão ser registrados em centros indexadores. Esta recomendação fará parte do Artigo 37 e ficará em observação, podendo ser expandida para os demais grupos em futuras edições do Código.

10. O Artigo 59, que trata dos fungos com ciclo de vida pleomórfico, será bastante alterado. Dentre as mudanças mais importantes, está sua tipificação, que não seguirá mais a prioridade estabelecida no Código de Viena (McNeill et al. 2006).

\section{Pontos que também merecem ser comentados:}

1. Antes da Sessão de Nomenclatura, uma sinopse das propostas, mencionando aspectos positivos e negativos, é publicada pelo Rapporteur général e o Vice-rapporteur do Código. Em Melbourne, alguns membros sugeriram que algumas propostas não haviam sido compreendidas em sua totalidade por eles e os comentários negativos sobre elas (McNeill \& Turland 2011) poderiam ter levado à não aprovação das propostas. Pelo menos duas delas foram rediscutidas e aprovadas durante a Sessão de Nomenclatura.

2. O Comitê Editorial ficou encarregado da redação final das modificações que serão introduzidas no Código de Melbourne. Os 14 membros desse comitê se reunirão na primeira semana de dezembro de 2011, nas dependências do Herbário BM (Natural History Museum, em Londres).

3. Os curadores dos herbários brasileiros devem se inscrever na época certa para que sejam avaliados e o número de votos institucionais a que têm direito possa ser considerado. Seria interessante que a Sociedade Botânica do Brasil 
(SBB), através da Comissão de Herbários, ajudasse a circular informações para que nossos herbários indiquem delegados para a votação presencial durante a Sessão de Nomenclatura.

4. Os votos individuais na Sessão de Nomenclatura são decisivos e os institucionais utilizados apenas quando a apuração está equilibrada. A pequena representatividade da comunidade latino-americana faz com que continuemos tendo pouca influência na tomada de decisões. Dessa maneira, é importante que nos organizemos para participar da próxima Sessão de Nomenclatura, que será realizada em Shenzengh, China, em julho de 2017, especialmente se considerarmos que o Brasil poderá ser um forte candidato a sediar o XX Congresso Internacional de Botânica, em 2023.

\section{Referências}

McNeill, J. \& Turland, N.J. 2011. Synopsis of Proposals on Botanical Nomenclature - Melbourne 2011: A review of the proposals concerning the International Code of Botanical Nomenclature submitted to the XVIII International Botanical Congress. Taxon 60(1): 243-286.

McNeill, J.; Barrie, F.R.; Burdet, H.M.; Demoulin, V.; Hawksworth, D.; Marhold, K.; Nicolson, D.H.; Prado, J.; Silva, P.C.; Skog, J.E.; Wiersema, J.E.H. \& Turland, N.J. 2006. International Code of Botanical Nomenclature (Vienna Code) adopted by the Seventeenth International Botanical Congress Vienna, Austria, July 2005. [Regnum Vegetabile. V. 146.] Ruggell, A.R.G. Gantner Verlag.

Special Committee on Electronic Publication. 2010. Proposals to permit electronic publications to be effectively published under specified condition. Taxon 59(6): 1907-1908. 